\title{
Dividing justly in bargaining problems with claims: Normative judgments and actual negotiations
}

Citation for published version (APA):

Gaechter, S., \& Riedl, A. M. (2006). Dividing justly in bargaining problems with claims: Normative judgments and actual negotiations. Social Choice and Welfare, 27, 571-594. https://doi.org/10.1007/s00355-006-0141-z

Document status and date:

Published: 01/01/2006

DOI:

10.1007/s00355-006-0141-z

Document Version:

Publisher's PDF, also known as Version of record

Document license:

Taverne

Please check the document version of this publication:

- A submitted manuscript is the version of the article upon submission and before peer-review. There can be important differences between the submitted version and the official published version of record.

People interested in the research are advised to contact the author for the final version of the publication, or visit the DOI to the publisher's website.

- The final author version and the galley proof are versions of the publication after peer review.

- The final published version features the final layout of the paper including the volume, issue and page numbers.

Link to publication

\footnotetext{
General rights rights.

- You may freely distribute the URL identifying the publication in the public portal. please follow below link for the End User Agreement:

www.umlib.nl/taverne-license

Take down policy

If you believe that this document breaches copyright please contact us at:

repository@maastrichtuniversity.nl

providing details and we will investigate your claim.
}

Copyright and moral rights for the publications made accessible in the public portal are retained by the authors and/or other copyright owners and it is a condition of accessing publications that users recognise and abide by the legal requirements associated with these

- Users may download and print one copy of any publication from the public portal for the purpose of private study or research.

- You may not further distribute the material or use it for any profit-making activity or commercial gain

If the publication is distributed under the terms of Article $25 \mathrm{fa}$ of the Dutch Copyright Act, indicated by the "Taverne" license above, 


\title{
ORIGINAL PAPER
}

\section{Simon Gächter • Arno Riedl \\ Dividing justly in bargaining problems with claims}

\section{Normative judgments and actual negotiations}

Received: 26 April 2004 / Accepted: 30 September 2005 / Published online: 16 May 2006

(C) Springer-Verlag 2006

\begin{abstract}
Theoretical research on claims problems has concentrated on normative properties and axiomatizations of solution concepts. We complement these analyses by empirical evidence on the predictability of three classical solution concepts in a bankruptcy problem. We examine both people's impartial normative evaluations as well as their actual negotiation behavior in a bargaining with claims environment. We measure people's judgments on the normative attractiveness of solution concepts with the help of a survey and also observe actual agreements in a bargaining experiment with real money at stake. We find that the proportional solution is the normatively most attractive rule, whereas actual negotiation agreements are closest to the 'constrained equal-award' solution.
\end{abstract}

\section{Introduction}

In this paper we empirically investigate bargaining problems with claims. These are an important class of more general rationing problems where agents have acquired

S. Gächter

CESifo, Munich, Germany

S. Gächter · A. Riedl

IZA, Bonn, Germany

S. Gächter

School of Economics, University of Nottingham, University Park,

Nottingham NG7 2RD, UK

E-mail: Simon.Gaechter@nottingham.ac.uk

A. Riedl ( $\bowtie)$

Department of Economics, Faculty of Economics and Business Administration, University of Maastricht, P.O. Box 616, 6200 MD Maastricht, The Netherlands E-mail: a.riedl@algec.unimaas.nl 
claims on resources that cannot all be satisfied. As pointed out by Moulin (2000) rationing problems are among the oldest distribution problems tackled with formal models of distributive justice and encompass a variety of specific contexts. For instance, problems of taxation (e.g., Young 1988) and the problem how to share the cost of a public good (e.g., Moulin 1987) can be interpreted in this way. A prominent interpretation - and one that inspired our paper - is as a (bargaining with) claims problem or bankruptcy problem (e.g., O'Neill 1982; Aumann and Maschler 1985). ${ }^{1}$

The prominence and practical relevance of the problem led to a stream of theoretical contributions about the right way to solve the problem. For a recent survey of this literature we refer the reader to Thomson (2003). The game theoretic approach formulates the claims problem as a game and relates the solutions to prominent solution concepts of games without claims (see, for instance, O'Neill 1982; Aumann and Maschler 1985; Curiel et al. 1987; Chun and Thomson 1992; Dagan and Volij 1993). The axiomatic approach tries to identify rules satisfying a set of intuitively reasonable axioms that can be applied to such claims problems (see among others, Dagan 1996; Moulin 2000; Chun et al. 2001; Herrero and Villar 2001). ${ }^{2}$

The axiomatic approach has derived three prominent rules to solve bankruptcy problems that we will investigate empirically in this paper. These rules, which we describe in detail in the next section are (1) the proportional rule, according to which resources are allocated among claimants in the proportion of their claims; (2) the constrained equal-losses rule, which distributes the loss equally among claimants; and (3) the constrained equal-awards rule, which allocates the resource equally among the claimants provided no one receives more than his or her claims.

Without doubt, the theoretical literature has improved our understanding of the axiomatic and game theoretic underpinnings of various normative rules. Yet, in practice, many people who have to deal with claims problems will use arguments on the perceived attractiveness of the rules. Hence, a normative solution should not only be theoretically appealing but also prove to be tenable and sustainable in the sense that all parties involved in the claims problem can accept it. This is even more so if several different theoretical concepts correspond to different attractive solutions of games or satisfy different attractive sets of axioms. Therefore, as a complementary approach it is useful to have positive evidence on solutions to claims problems.

In this paper we assess the three rules to claims problems empirically. There are two dimensions to this empirical assessment. The first dimension is the moral or normative intuition people have on what they think a fair solution is. If we devise rules they should hold for a broad class of problems and have to be normatively acceptable for many people who are potentially subjected to the rule. The second dimension is actual behavior that may or may not be influenced by justice arguments. If we want to understand how people will behave if they negotiate on their

\footnotetext{
${ }^{1}$ Chun and Thomson (1992) distinguish a claims problem from a bankruptcy problem as the former is the non-transferable utility variant of the latter. For convenience we do not distinguish between the two in this paper.

${ }^{2}$ Most of the literature applies cooperative game theory. For an important exception using a non-cooperative approach, see Dagan et al. (1997).
} 
behalf in a bankruptcy problem we need to know how the claims influence the bargaining outcome. This paper provides empirical evidence on both dimensions.

Different tools are needed for appropriately covering both dimensions. Assessing normative views requires impartiality. In contrast, when people actually negotiate over the division of a surplus that they will enjoy after an agreement has been reached, people are certainly not impartial. To assess impartial normative views we employ a vignette technique. Vignettes describe the bargaining with claims problem and then the respondents are asked to make a judgment about a fair division of the available pie. Our second tool is laboratory experiments where subjects actually negotiate in a bargaining with claims environment.

Vignettes have the advantage that they measure the unbiased responses of impartial participants. Exactly because the question is hypothetical, responses cannot be confounded by self-interest, but reflect the normative judgments of the respondents. This is why vignettes are very popular in empirical research on ethical rules of theories of justice (e.g., Yaari and Bar-Hillel 1984; Kahneman et al. 1986; Schokkaert and Overlaet 1989; Schokkaert and Capeau 1991; Gaertner et al. 2001; Gaertner and Jungeilges 2002; see Konow (2002) for an extensive survey).

Our second instrument measures people's actual behavioral responses in a laboratory bargaining experiment, where financially motivated subjects have to negotiate in a free-form bargaining with claims environment and where the agreements determine the bargainers' compensation. Thus we can examine which normative solution concept corresponds best to the agreements in real, not hypothetical, negotiations. Previous experiments in the area of fairness and justice research that is related to our experiments comprise Frohlich et al. (1987), Frohlich and Oppenheimer (1990), Gaertner and Klemisch-Ahlert (1992), Klemisch-Ahlert (1996) and Beckman et al. (2002). In the experiment we may observe a confluence of motivations, like envy, egoism and toughness. The comparison of surveys and experiments will allow us to assess the difference of moral judgments and actual behavior.

Our research design also varies the claims. We look at two different claims points because theoretically the normative attractiveness of bankruptcy rules is independent of the specific claims. Empirically, however, different distributions of claims may make particular solutions more or less attractive. One claims point is very asymmetric in that one claimant has a much higher claim than the other one. The second claims point is more balanced. This offers us the possibility to observe if and how the asymmetry of the claims point influences the normative judgments and actual behavior.

In our research design the normative solutions make different point predictions about how the resource should be allocated. Our empirical strategy is to observe the normative judgments in the vignette study and the negotiated agreements in the experiment and then to investigate which of the normative rules comes closest to the observed outcome. In the vignettes we find that for both claims levels the subjects' answers come closest to the proportional rule. By contrast, in the experiments, the agreements are for both claims points close to the solutions proposed by the 'constraint equal-awards' rule and the equal split.

In examining the negotiated agreements we also consider an area-based descriptive bargaining theory as an alternative to the point predictions of the bankruptcy rules. We find that a solution that adjusts the Negotiation Agreement Area Theory developed by Uhlich (1990) by the claims points does very well in predicting behavior for claims points that are not 'too asymmetric'. 
One may argue that with our questionnaires and the experiments we can only indirectly assess the attractiveness of the different bankruptcy rules, because we 'only' judge the vicinity of a judgment or agreement to a proposed solution. To gain direct evidence on the attractiveness of the normative rules, we investigate in the last part of our study the bargaining problem with claims from a different viewpoint. In a further survey study we confronted respondents with the description of the rules and asked them to rank the proposed rules according to their perceived attractiveness. Thus, in this 'beauty contest' of rules subjects can explicitly compare the rules. Again, we find that the proportional rule receives the strongest support.

To our knowledge this study is the first to combine questionnaires, experiments and different claim points in one design. The only other experiments that explicitly investigate bargaining with claims problems we are aware of are Klemisch-Ahlert (1996), Herrero et al. (2004) and Gächter and Riedl (2005). Klemisch-Ahlert (1996) is interested in the evaluation of distributive principles subjects apply in bargaining environments. Specifically, she investigates how the subjects' distributive principles depend on their bargaining position and how the subjects' principles and the bargaining environment influence the agreements. Gächter and Riedl (2005) use a bargaining with claims framework to investigate the role of entitlements in the negotiation process. The paper closest to ours is Herrero et al. (2004). These authors investigate the experimental performance of non-cooperative procedures that underpin prominent bankruptcy rules and how different framings of the experiment influence the outcomes.

Our paper is structured as follows. In the next section we formally introduce the claims problem and the three prominent solutions investigated in our study. Following Herrero and Villar (2001) we call them the three musketeers. Section 3 describes the details of our research design. Section 4 discusses the main results. Section 5 introduces the 'beauty contest of normative rules' and the results of this contest. Section 6 concludes.

\section{The claims problem and the 'three musketeers'}

Informally, a claims problem is a distribution problem that involves the allocation of a single (perfectly divisible) good, the estate, in a situation where the available resource is not sufficient to meet all agents' claims simultaneously. Such a problem can be resolved by the application of a rule that prescribes how the resource should be allocated among the claimants. The idea behind such a rule is that it does not depend on particular circumstances of the situation where the problem occurs but only on the economically relevant variables, that is the agents' claims and the value of the resource. For a given situation the rule processes the relevant circumstances to a result, which is the solution of the problem for the given situation.

In the following we provide formal definitions of a claims problem and the prominent rules for solving it. We follow the presentation of Thomson (2003) (see also, e.g., Herrero and Villar 2001). Denote the net worth of the estate (good, resource) by $E$. The set of agents is $N$, and each agent $i \in N$ has a claim or demand $c_{i} \geq 0$ on $E \in \mathcal{R}$. The vector of claims is then denoted $c=\left(c_{i}\right)_{i \in N}$ and $C=\sum_{i \in N} c_{i}$. 
A claims problem is a pair $(c, E) \in \mathcal{R}_{+}^{N} \times \mathcal{R}_{+}$with $\sum_{i \in N} c_{i} \geq E$. The class of these problems is denoted by $\mathcal{B}^{\mathcal{N}}$. A solution to the claims problem is a function $F$, a rule, defined on the class of claims problems that associates with each problem in the class a division of the estate between the claimants. It has the following properties: (1) $0 \leq F(c, E) \leq c$, (2) $\sum_{i \in N} F_{i}(c, E)=E$.

In this paper we investigate three prominent and classical solutions to the claims problem: the constraint equal-losses rule, the proportional rule and the constraint equal-awards rule which are the 'three musketeers', according to Herrero and Villar (2001). These rules are of particular interest because they are the ones used most often in practice. Furthermore, these rules have in common that they are the only three rules that simultaneously satisfy an intuitively reasonable set of axioms. These are the axioms of equal treatment of equals, scale invariance, composition, path-independence and consistency (see Moulin 2000; Herrero and Villar 2001).

The constraint equal-losses (CEL) rule distributes the estate such that all agents suffer the same losses, subject to the condition that no claimant ends up with a negative reward. Formally, for all $(c, E) \in \mathcal{B}^{N}$ and all $i \in N$ there exists a $\lambda>0$ such that $\mathrm{CEL}_{i}(c, E)=\max \left\{0, c_{i}-\lambda\right\}$. By the definition of a rule it follows that $\lambda$ is such that $\sum_{i \in N} \max \left\{0, c_{i}-\lambda\right\}=E$.

The proportional (PROP) rule awards the estate in proportion to the claims. That is, it equalizes the ratios between claims and awards. The formal definition is as follows: For all $(c, E) \in \mathcal{B}^{N}$ there exists a $\lambda>0$ such that $\operatorname{PROP}(c, E)=\lambda c$. By the definition of a rule it follows that $E / C=\lambda \in] 0,1]$.

The constraint equal-awards (CEA) rule divides the estate equally between all claimants with the proviso that no agent receives more than her claim. Formally, for all $(c, E) \in \mathcal{B}^{N}$ and all $i \in N$ there exists a $\lambda>0$ such that $\mathrm{CEA}_{i}(c, E)=$ $\min \left\{c_{i}, \lambda\right\}$. The definition of a rule implies that $\lambda$ solves $\sum_{i \in N} \min \left\{c_{i}, \lambda\right\}=E$.

Note that the idea of equality underlies each of the above rules. However, each rule applies the idea of equality to different variables. CEL focuses on the equality of losses, the PROP rule ensures the equality of ratios and the CEA rule puts its emphasis on the equality of awards.

We also consider the simple equal division of the estate, an outcome often observed in symmetric bargaining experiments (e.g., Nydegger and Owen 1975), as a fourth possible rule and benchmark:

The equal-awards (EQUA) rule just divides the estate equally between all agents. That is, for all $(c, E) \in \mathcal{B}^{N}, \operatorname{EQUA}(c, E)=(E / n, \ldots, E / n)$.

In our experiments and vignettes (for details see the next section) we investigate two-person bargaining problems with claims where the pie to be distributed is 2050 'points'. We consider two different claims points, $(1980,510)$ and $(1640,850)$, which both sum to 2490 .

Figure 1 graphically depicts our bargaining problems with claims and the solutions discussed above for our parameters. In the figure we normalize the pie of 2050 to one.

\section{The research design}

Recall that we are interested in two dimensions of the empirical performance of the four bankruptcy rules - the normative dimension and the behavioral dimension. 


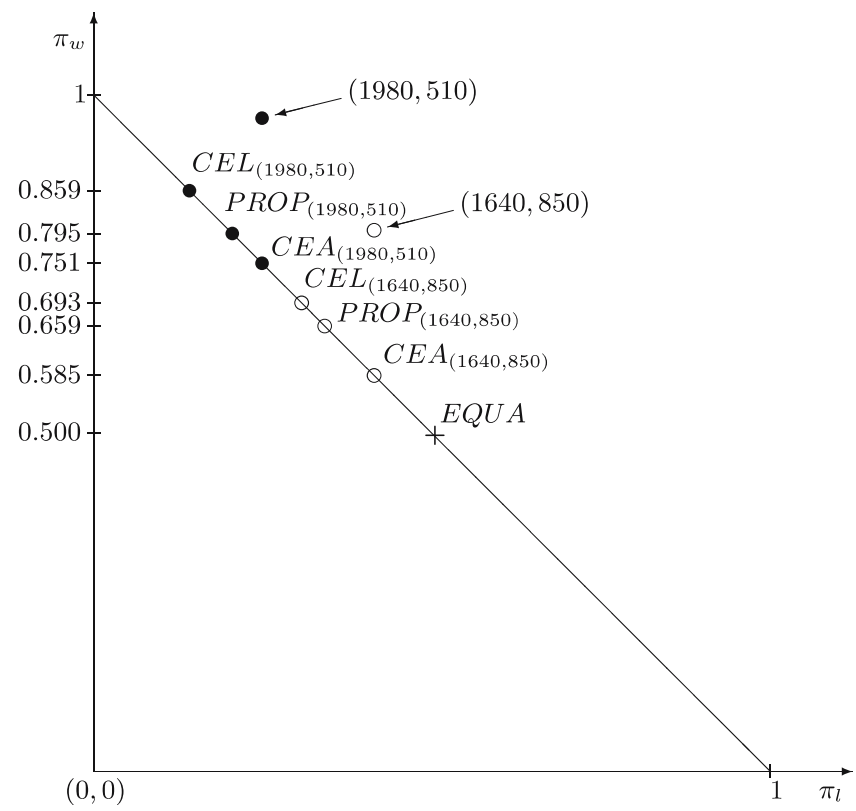

Fig. 1 Graphical representation of the bargaining with claims problems and the solutions

We measure the normative dimension with the help of questionnaires that present a vignette ('a scenario') to the respondent. We assess the behavioral dimension by looking at actual negotiations of financially motivated bargainers in a bargaining with claims environment. A second important feature of our design is the difference in the asymmetry of the claims points. Since we are employing two research methods and investigate two claims points we have four treatments, which we summarize in Table 1. We use the labels $1980 \mathrm{E}$ and $1640 \mathrm{E}$ for the experiments where the claims points were $(1980,510)$ and $(1640,850)$, respectively, and the labels $1980 \mathrm{~V}$ and $1640 \mathrm{~V}$ for the vignette studies.

We start by describing the survey study and will then explain the experimental setup and the procedures of our study.

\subsection{The 'bargaining with claims' environments}

The decision setup of both the vignette study as well as the experiments is a 'bargaining with claims' environment as it is graphically described in Fig. 1.

Table 1 Our design

Method

Claims

Treatment name (\# of obs.)

(1980, 510)

Experiment

$1980 \mathrm{E}(N=28)$

Vignette

1980V $(N=29)$

$(1640,850)$

Experiment

Vignette

$1640 \mathrm{E}(N=12)$ 1640V $(N=30)$ 
In the surveys subjects were given the following vignette (translated from German), either with the claims $(1980,510)$, or $(1640,850)$ :

\begin{abstract}
Please imagine the following situation. You and your bargaining partner have to negotiate over the division of a total budget of 2,490 money units. Historically, the total budget has always been split according to performance. The bargaining partner who has shown the better performance, has so far received an amount of 1,980 [1,640] money units and the bargaining partner with the lower performance has received 510 [850] money units. Take it for granted that the performance (i.e., who has shown the higher or lower performance) can be objectively determined. It now turns out that the hitherto valid claims cannot be satisfied anymore. The new total budget amounts now to 2,050 money units (i.e., is 440 money units lower than the old budget). According to your opinion, what would be a 'fair' new division from the vantage point of a non-involved, neutral arbitrator? (Please give exact amounts and no intervals! The amounts have to add up to 2,050 money units) [emphasis in original].

Your opinion on the division of the arbitrator:

Amount for the bargaining partner with the better performance:

Amount for the bargaining partner with the lower performance:
\end{abstract}

2050.

The experiment used the same decision problem as in the survey studies. However, while in the vignette the claims point can just be given as part of the description of the problem, in the experiment this might by considered as cheap talk and is therefore not a useful thing to do. In our experiment, therefore, subjects first earn the claims in a competitive task. With a certain probability these claims are actually paid out to the subjects. With the remaining probability subjects are told that the claims are infeasible and that they have to negotiate an agreement in a symmetric free-form bargaining. In case they fail to reach an agreement, they earn nothing. We will now describe the experiment in more detail.

The experiments were conducted as follows. ${ }^{3}$ At the beginning of the experiment, subjects were randomly allocated to computer booths, which were located in two different rooms. After subjects had finished reading the instructions the first part of the experiment started, in which subjects earned claims in a general knowledge quiz. In particular, subjects had to answer 24 questions from a variety of fields, including astronomy, history, sports, music, politics, etc. We were very careful to select questions that students with a high school degree should in principle be able to answer, and that subjects would recognize as testing their high school knowledge. The knowledge quiz was a multiple choice test with five possible choices and only one correct answer. All subjects had to answer the same questions. They had 12 min to answer all questions. Unanswered questions were counted as wrong answers.

After the quiz we told the subjects which of the two bargaining partners did better in the knowledge quiz. We only informed them about the rank of their performance (i.e., whether they did better or worse than their bargaining partner) and not about the actual number of correct answers. Apart from simplicity reasons, we wanted to hold the claims constant across subjects and between bargaining pairs.

\footnotetext{
${ }^{3}$ The experimental instructions can be downloaded from http://www.fee.uva.nl/creed/pdffiles/ instr2bankruptcy.pdf.
} 
A chance move then determined whether the budget shrunk to 2,050 points or remained at 2,490 points. ${ }^{4}$ The former implied that subjects had to negotiate over the division of the smaller pie of 2,050 points. If the latter outcome occurred the claims according to the knowledge quiz were actually paid out. ${ }^{5}$ By making the claims a potential payment in the experiment, we gave the subjects an incentive to see the knowledge quiz as an important part of the experiment. Moreover, previous research shows that a knowledge quiz is indeed viewed as representative of true desert (e.g., Hoffman et al. 1994; Clark 1998; Ball et al. 2001). Thus, given the previous evidence on the effectiveness of non-paid knowledge quizzes and given that in our case the claims could actually be paid out, we believe that our procedure is an effective way to implement the claims.

To examine whether the claims affect bargaining behavior at all we conducted a control experiment without claims. This experiment was set up in exactly the same way as the one just described, except that there was no knowledge quiz and no claims to be earned. Twenty-four subjects participated in this experiment.

The bargaining was free-form, i.e., there was no fixed bargaining protocol (see, e.g., Roth and Murnighan 1982). We implemented a free-form bargaining protocol because (1) it is naturally occurring and (2) because the cooperative bargaining theories do not specify a bargaining protocol. Bargaining was conducted over a local area network with the help of the experimental software 'Rabbit' (Brandel 2000). The negotiators were allowed to make any (non-negative) proposal as long as the sum of shares was smaller or equal to 2,050 points. The negotiators had 15 min to reach an agreement. The instructions told the subjects that in case they fail to reach an agreement within the time limit they would earn nothing in this experiment, except their show-up fee. Hence, the 'threat point' in this experiment is $(0,0)$. Random pairing, anonymity, duration and disagreement payoffs were common knowledge.

\subsection{Procedures and payments}

The vignettes where administered to 59 first year undergraduate students of law, business administration and computer science of the University of Vienna who were, at the end of class, asked to answer the above problem. Participation was voluntary and anonymous. ${ }^{6}$ Each participant only took part either in $1980 \mathrm{~V}$ or in $1640 \mathrm{~V}$. It took the students roughly $10 \mathrm{~min}$ to answer the question.

The experiments were conducted in the computerized lab of the Institute for Advanced Studies in Vienna. The 80 experimental subjects had the same back-

\footnotetext{
${ }^{4}$ In the experiment the chance move was implemented as follows. After subjects were informed about the rank of their performance, each bargaining partner in a dyad had to roll a six-sided die. It was explained that the claims would be actually paid out if the sum of the numbers of both dice was greater or equal to 11 . If the sum of the dice numbers was smaller than 11 , the bargaining partners had to bargain over how to split the smaller pie of 2,050 points.

${ }^{5}$ In case the dice determined that the claims will be paid out, we told the pairs to bargain hypothetically over the sharing of 2,050 points. We ensured the subjects that they will receive their claims regardless of the outcome in the hypothetical bargaining. This procedure ensured that no bargaining pair left earlier than the others, which would have been technically difficult and disturbed the experiment. We only observed three pairs that had to bargain hypothetically.

${ }^{6}$ To avoid any experimenter demand effect we did not administer this questionnaire to our own students but instead asked colleagues to administer the questionnaire for us in their class.
} 
ground as our survey participants. Nobody who participated in the vignette study took part in the experiments. Moreover, each subject only participated in one experiment. The experimental subjects were paid according to their decisions in the experiment. The average earning (including a show-up fee) was approximately Euro 19. On average, an experiment lasted $75 \mathrm{~min}$, including reading the instructions, performing the experiment and answering a post-experimental questionnaire.

\section{Results}

We first analyze the normative judgments and then describe the results of the negotiations. We start our analysis at an aggregate level. In a further important step we will evaluate the predictive power of the four solutions by performing an individual-level analysis.

For convenience, in the remainder of the paper we refer to the subject with the high claim (either 1,980 or 1,640) as the 'winner' and to the subject with the low claim (either 510 or 850 ) as the 'loser' of the performance quiz. Moreover, we will adopt the convention to express all allocations in 'winner shares', i.e., the share of the total pie of 2,050 that goes to the 'winner' of the quiz, i.e. the better performer.

\subsection{Normative judgments}

What are the normative views our respondents hold about the fair division in the two bargaining with claims environments? Our first result records the evidence.

Result 1 The claims strongly affect the normative views of a fair division. If claims are 1,640 , the average winner share is $65.2 \%$, which is closest to PROP. If claims are 1,980 , the respondents on average think the winner should get $75.4 \%$. This comes closest to CEA. Fairness judgments also become more heterogeneous when claims are very asymmetric.

Support Figure 2 provides a graphical support for our first result. It shows a boxplot for each of the two claim levels. ${ }^{7}$ The medians of the two distributions are far apart from each other. With the 1,980 claims the whole distribution is shifted upwards. Both a non-parametric Mann-Whitney test and a Kolmogorov-Smirnov test show that the null hypothesis of equal distributions can be rejected at all conventional levels. In the impartial judgments of the vignettes, the answer in $1980 \mathrm{~V}$ is on average 10.2 percentage points higher than in $1640 \mathrm{~V}$. A further interesting observation is that the variance is considerably higher in $1980 \mathrm{~V}$ than in $1640 \mathrm{~V}$. The standard deviation when claims are strongly asymmetric is $9.7 \%$, while it is $6.5 \%$ in $1640 \mathrm{~V}$. A variance ratio test rejects equality of variances of the fairness judgments in the two claims conditions ( $F$ test, $p=0.0351$ ). Thus, the asymmetry of claims increases the heterogeneity in fairness judgments.

\footnotetext{
${ }^{7}$ The box-plot is a convenient compact way of describing the distribution of outcomes. The rectangle contains $50 \%$ of the observations. The lower end of the rectangle is the 25 th percentile and the upper end the 75th percentile. The horizontal line in the box indicates the median. The vertical line outside the box indicates the adjacent values, and the dots outside the adjacent lines are 'outliers'. The distribution of all normative judgments can be found in the Appendix.
} 


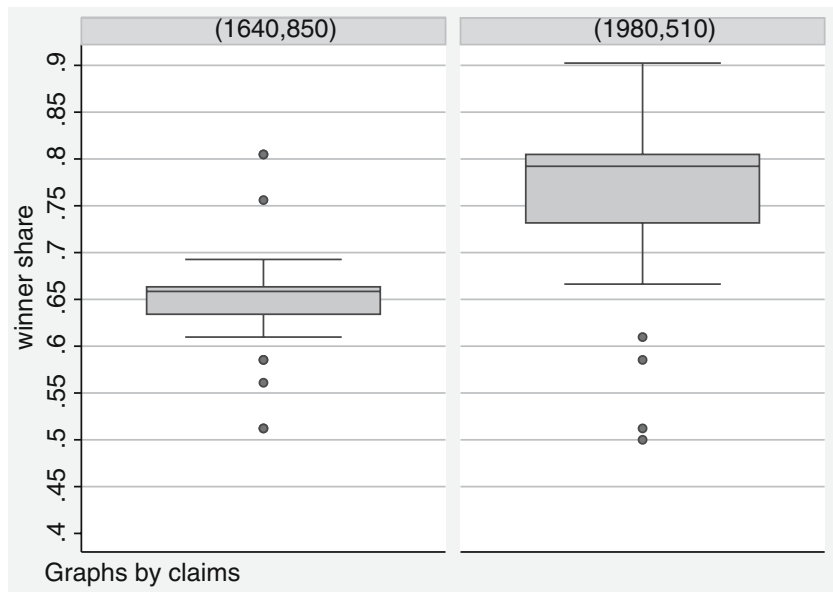

Fig. 2 Box-plots of distribution of normative judgments

Table 2 Deviations from predicted solutions in normative judgment

\begin{tabular}{lcc}
\hline Claims & $(1640,850)$ & $(1980,510)$ \\
\hline Answer & 0.652 & 0.754 \\
(SD) & $(0.065)$ & $(0.097)$ \\
CEL & 0.693 & 0.859 \\
diff. $^{\text {a }}$ & $-0.041^{* *}$ & $-0.104^{* * *}$ \\
& & \\
PROP & 0.659 & 0.795 \\
diff. & -0.007 & $-0.041^{*}$ \\
CEA & 0.585 & 0.751 \\
diff. & $0.067^{* * *}$ & 0.003 \\
EQUA & 0.500 & 0.500 \\
diff. & $0.152^{* * *}$ & $0.254^{* * *}$ \\
$N$ & 30 & 29 \\
\hline
\end{tabular}

${ }^{* * *} p<0.001,{ }^{* *} p<0.01,{ }^{*} p<0.05 ; t$ tests, two-sided

a Average difference of answer to the respective rule, positive if average answer is larger than solution

We now look at which rule organizes the data best, i.e., which solution comes closest to the observations on the aggregate level. Table 2 summarizes for both claim levels the mean deviation of the observed outcome from a particular theoretical solution. For instance, with claims of $(1980,510)$ CEL proposes that the winner should get a share of 0.859 of the new pie of 2,050. The answers from the survey fall short of the CEL prediction by an average of -0.104 and this difference is significant according to a two-tailed $t$ test.

In $1640 \mathrm{~V}$ answers come closest to PROP (which predicts a share of $65.9 \%$ ), whereas in the highly asymmetric claims of $1980 \mathrm{~V}$ the answers are very close to CEA, which predicts $75.1 \%$. Note this implies that the normative attractiveness of 
the different rules is not constant across claims. Finally, the equal split EQUA is farthest apart from the observed answers. This holds for both claim points.

Experimental evidence and theories of prominent numbers (see, e.g., Albers and Albers 1983) suggest that subjects do not always calculate ratios and shares exactly but rather approximate them by rounding to the next prominent number(s). What the relevant prominent numbers are (that is, the prominence level $\Delta$ ) depends on the design of the decision situation and the generated data set. Selten (1987) describes a method for the determination of the prominence level of a data set. We applied that method to the winner shares (in points) of the normative judgments and find that the prominence level in our vignette is given by $\Delta=50$. A related issue concerns the calculation of the claim ratios, which are no integer numbers $(1640 / 850=1.9294$ and $1980 / 510=3.8882)$. Here we assume that our respondents round the ratios to $2: 1$ and $4: 1$, respectively.

We shortly discuss how our previous results with respect to PROP change when taking the prominence structure of our vignette into account. We denote the lower bound of the proportional rule for $\Delta=50$ by $\mathrm{PROP}_{1}^{\mathrm{p} 50}$ and the corresponding upper bound by $\mathrm{PROP}_{\mathrm{u}}^{\mathrm{p} 50}$. In $1640 \mathrm{~V}$ any winner shares between $\mathrm{PROP}_{1}^{\mathrm{p} 50}=0.659$ and $\mathrm{PROP}_{\mathrm{u}}^{\mathrm{p} 50}=0.683(1,350$ and 1,400 in points $)$ are then consistent with PROP. For $1980 \mathrm{~V}$ the PROP-consistent winner shares are between $\mathrm{PROP}_{1}^{\mathrm{p} 50}=0.780$ and $\mathrm{PROP}_{\mathrm{u}}^{\mathrm{p} 50}=0.805(1,600$ and 1,650 in points $)$. In $1640 \mathrm{~V}$ we find that actual normative judgments do statistically significantly differ from the upper bound $\operatorname{PROP}_{\mathrm{u}}^{\mathrm{p} 50}$ ( $p=0.0140 ; t$ test, two-sided) but not from the lower bound $\operatorname{PROP}_{\mathrm{u}}^{\mathrm{p} 50}$ ( $p=$ $0.5867 ; t$ test, two-sided). Similarly, for $1980 \mathrm{~V}$ we also find that actual judgments are statistically significantly different from $\operatorname{PROP}_{\mathrm{u}}^{\mathrm{p} 50}(p=0.0089 ; t$ test, twosided) but not from the lower bound $\operatorname{PROP}_{1}^{\mathrm{p} 50}(p=0.1569 ; t$ test, two-sided $)$. Only the last result differs from the results reported in Table 2. There we found that actual normative judgments are statistically significantly below the point prediction PROP. A similar analysis with respect to the other rules does not change the results depicted in Table 2. Hence, when taking the prominence level of the data set into account the observed normative judgments can be viewed as consistent with the proportional rule as well as with CEA.

\subsection{Negotiated agreements}

While the vignettes elicit the impartial normative views, in actual negotiations many other motives, in addition to the normative views can play a role and influence the agreements. Result 2 summarizes our main observations from the bargaining experiment. $^{8}$

Result 2 The bargaining agreements are affected by the claims but not by the difference in the asymmetry of the claims. In 1980E, the average winner share is $58.5 \%$, which comes closest to EQUA. In $1640 \mathrm{E}$ the winner share is $57.3 \%$. This

\footnotetext{
${ }^{8}$ Our main interest is on the reached agreements. Most of the agreements were reached clearly before the deadline of $900 \mathrm{~s}$. Out of the 31 agreements 5 were reached in the last $5 \mathrm{~s}$, which indicates a weak deadline effect also observed in earlier free-form bargaining experiments (e.g., Roth et al. 1988). In nine cases no agreement was reached.
} 


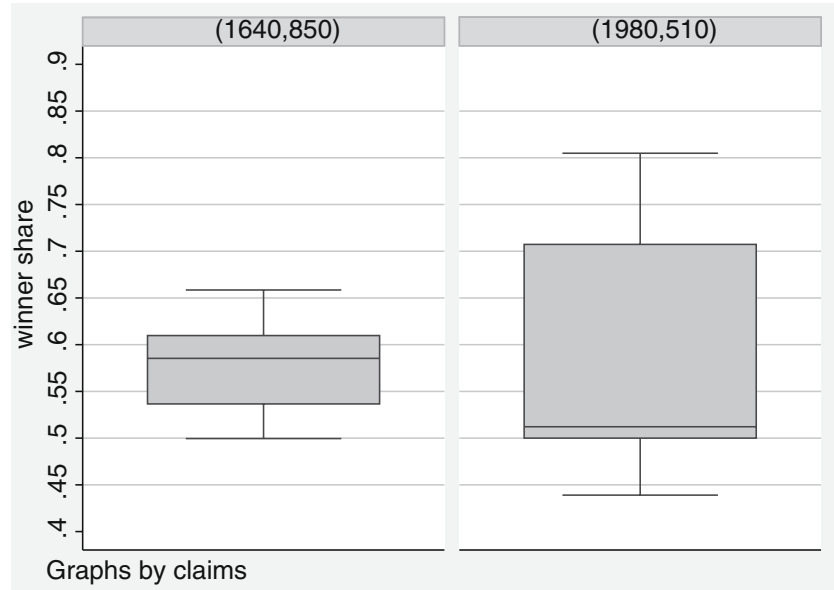

Fig. 3 Box-plots of distribution of negotiated agreements

is closest to CEA. The variance in agreements strongly increases in the asymmetry of claims.

Support Figure 3 depicts the distribution of agreements for the two claim levels. (The distribution of all bargaining outcomes can be found in the Appendix.) Recall that we also conducted a control experiment without claims to examine whether asymmetric claims matter at all. In line with previous symmetric free-form bargaining experiments (e.g., Nydegger and Owen 1975) we find that $100 \%$ of the agreements implement the equal split. Thus as Fig. 3 shows, the presence of asymmetric claims strongly affects the bargaining outcomes. Two further observations are noteworthy. First, the variance in the agreed winner shares is considerably higher in $1980 \mathrm{E}$ than in $1640 \mathrm{E}$. In $1980 \mathrm{E}$ the standard deviation is $11.5 \%$, which is twice as high than in $1640 \mathrm{E}$, where it is $5.7 \%$. A variance ratio test clearly rejects equality of variances of the agreements in the two claims conditions ( $F$ test, $p=0.0253$ ). Thus, the more asymmetric claims are the more heterogeneous agreements become. Second, the mean agreements are very similar. In 1980E the agreed winner share is $58.5 \%$, while it is $57.3 \%$ in $1640 \mathrm{E}$. Both a non-parametric Mann-Whitney test and a Kolmogorov-Smirnov test show that the null hypothesis of equal distributions cannot be rejected ( $p$ values are 0.825 and 0.389 ).

When we look at which solution comes closest to the observed average agreements we find that in 1980E EQUA predicts best, whereas in 1640E CEA does best. However, we observe also that actual winner shares are significantly above the share of one half. Table 3 records the details.

We close this section by comparing the normative judgments and actual agreements. First, a Kruskal-Wallis test shows that the null hypothesis of equal distributions in all of our four treatments can be rejected at any conventional level $(p=0.0001)$. Second, a comparison of normative judgments and actual agreements for the 1,640-claim (i.e., $1640 \mathrm{~V}$ and 1640E) shows that the actual agreements are $7.9 \%$ lower than the normative judgments. This difference is significant according to a two-sided Mann-Whitney test ( $p=0.001)$. When claims are very asymmetric (i.e., in 1980E and 1980V), the gap between actual agreements and 
Table 3 Deviations from predicted solutions in negotiations

\begin{tabular}{lcc}
\hline Claims & $(1640,850)$ & $(1980,510)$ \\
\hline Agreement & 0.573 & 0.585 \\
(SD) & $(0.057)$ & $(0.115)$ \\
CEL & 0.693 & 0.859 \\
diff. $^{\text {a }}$ & $-0.120^{* * *}$ & $-0.274^{* * *}$ \\
PROP & 0.659 & 0.795 \\
diff. & $-0.086^{* *}$ & $-0.210^{* * *}$ \\
CEA & 0.585 & 0.751 \\
diff. & -0.012 & $-0.166^{* * *}$ \\
EQUA & 0.500 & 0.500 \\
diff. & $0.073^{* *}$ & $0.085^{* *}$ \\
$N^{\mathrm{b}}$ & 9 & 22 \\
\hline
\end{tabular}

${ }^{* * *} p<0.001,{ }^{* *} p<0.01,{ }^{*} p<0.05 ; t$ tests, two-sided

a Average difference of answer to the respective rule, positive if average answer is larger than solution

$\mathrm{b}$ The number of observations is less than the number of bargaining pairs due to three disagreements in $1640 \mathrm{E}$ and six disagreements in $1980 \mathrm{E}$

normative judgments amounts to 17 percentage points, which is significant at any level. Thus, the asymmetry in claims also increases the divergence of actual agreements and normative judgments.

\subsection{Which rule predicts best? An individual-level analysis}

In this section we systematically examine the relationship between proposed solutions and observed outcomes. For doing so, we look at individual-level data to avoid potential averaging effects that might be present in the analyses of Tables 2 and 3. We proceed as follows. We calculate for each subject in the surveys (each bargaining pair in the experiments) the absolute differences of his or her answer (reached agreements) from the four solutions. We then rank the solutions according to the smallest difference of actual and proposed division. For instance, if a subject's answer comes closest to CEA, and is farthest apart from EQUA, CEA is ranked first and EQUA is ranked fourth for this subject. Finally, we calculate, for each treatment, the average rank of each solution. This provides us with a measure for the relative attractiveness of the different solutions at an individual level. We summarize this analysis in the following result.

Result 3 (a) In the normative judgments PROP comes closest to the observed results. This holds for both claims points. (b) In the negotiations the agreements are closest to CEA for both claims points.

Support Table 4 displays the distribution of ranks per treatment and per solution. For instance, in $1980 \mathrm{~V}$, CEL is first-ranked for the answers of 4 subjects, secondranked for the answers of 2 subjects, third-ranked for the answers of 18 subjects 
Table 4 Ranking of solutions

\begin{tabular}{|c|c|c|c|c|c|c|c|c|}
\hline \multirow[t]{2}{*}{ Claims } & \multicolumn{4}{|c|}{ Normative judgments } & \multicolumn{4}{|c|}{ Actual negotiations } \\
\hline & $\overline{\mathrm{CEL}}$ & PROP & CEA & $\overline{\text { EQUA }}$ & $\overline{\mathrm{CEL}}$ & PROP & CEA & EQUA \\
\hline \multicolumn{9}{|l|}{$(1980,510)$} \\
\hline 1 st rank & $4^{\mathrm{a}}$ & 14 & 7 & 4 & 0 & 2 & 5 & 15 \\
\hline 2nd rank & 2 & 11 & 16 & 0 & 1 & 5 & 16 & 1 \\
\hline 3rd rank & 18 & 4 & 6 & 1 & 5 & 15 & 1 & 0 \\
\hline 4th rank & 5 & 0 & 0 & 24 & 16 & 0 & 0 & 6 \\
\hline Mean rank & 2.8 & 1.7 & 2.0 & 3.6 & 3.7 & 2.6 & 1.8 & 1.9 \\
\hline Ranking of rules & Third & First & Second & Fourth & Fourth & Third & First & Second \\
\hline \multicolumn{9}{|l|}{$(1640,850)$} \\
\hline 1 st rank & 6 & 18 & 4 & 2 & 0 & 2 & 4 & 3 \\
\hline 2nd rank & 14 & 9 & 6 & 1 & 1 & 3 & 4 & 1 \\
\hline 3rd rank & 5 & 3 & 20 & 2 & 2 & 4 & 1 & 2 \\
\hline 4th rank & 5 & 0 & 0 & 25 & 6 & 0 & 0 & 3 \\
\hline Mean rank & 2.3 & 1.5 & 2.5 & 3.7 & 3.6 & 2.3 & 1.7 & 2.6 \\
\hline Ranking of rules & Second & First & Third & Fourth & Fourth & Second & First & Third \\
\hline$\chi^{2}$ test $^{\mathrm{b}}: p$ values & 0.00 & 0.66 & 0.00 & 0.57 & 0.41 & 0.42 & 0.20 & 0.12 \\
\hline
\end{tabular}

${ }^{a}$ Numbers indicate the number of observations for which the result (i.e., answer in vignette or agreement in bargaining) is closest, second closest, third closest and fourth closest, respectively, to the respective rule

${ }^{b} \chi^{2}$ tests compare the distribution of ranks between the different claims for each rule

and fourth-ranked for the answers of 5 subjects. Table 4 also reports the mean ranks and the overall ranks for the solutions, based on the mean ranks.

Table 4 clearly shows that in the normative judgments of the vignette treatments, PROP is the first ranked solution and EQUA receives the fourth rank. This holds for both claims points. In the negotiation experiments quite a different picture emerges. Here we find for both claims points that CEA is the solution than comes closest to the reached agreements and thus receives the first rank.

We know from Result 1 that on average the normative attractiveness of a solution is not independent of the asymmetry of the claims points. Here the question arises, whether there is a similar phenomenon with respect to the rank of the solutions. That is, does the rank of a solution implied by a particular rule depend on the asymmetry of claims? This is an important question because the normative rules are independent of the asymmetry in claims. Here we can report the following finding.

Result 4 (a) In the experiments, the distribution of ranks is not significantly different between 1980E and 1640E. This holds for all four solutions. (b) In the normative judgments, however, we find significant differences between $1980 \mathrm{~V}$ and 1640V in the distribution of ranks for CEL and CEA. PROP and EQUA are not significantly differently ranked. This indicates that in the vignettes the preferred rule is not independent of the claims.

Support In Table 4 we report pairwise $\chi^{2}$ tests of the distribution of rank orders for each of our solutions and per method of investigation. The results show that in the experiments the distribution of ranks does not differ between claim levels in 
all four rules ( $p \geq 0.12$ ). By contrast, in the normative judgments of the vignette studies, only the ranks of PROP and EQUA are equally distributed between claims. CEL and CEA are not stable since the distribution of ranks is significantly affected by the claims points.

At first sight Result 4 seems puzzling. We propose the following interpretation. Let us concentrate on the normative judgments first. Here we find that between claims, only CEL and CEA change ranks; PROP and EQUA are ranked equally across claims. Recall that CEL implements the most unequal division of the surplus of all four rules, whereas CEA is the most equal 'musketeer' (apart from EQUA, of course). When claims are very asymmetric, as in $1980 \mathrm{~V}$, people find the more equalizing CEA more attractive than the unequal CEL, whereas if claims are more equal, as in $1640 \mathrm{~V}$, people appreciate CEL more than CEA. In the experiment CEA is ranked first, whereas CEL is ranked last in both claims conditions. However, in the experiments we find that PROP and EQUA change ranks across claims (though the change in ranks is not statistically significant). When claims are very asymmetric (in 1980E), EQUA is more attractive than PROP, whereas when claims are moderately asymmetric (in 1640E), PROP is better ranked than EQUA. Thus, in both the normative judgments and the actual negotiations, when claims are very asymmetric, people prefer, ceteris paribus, the more egalitarian solutions, whereas they appreciate the more unequal rules when claims are moderately asymmetric.

\subsection{An alternative look at negotiated agreements}

In our analysis of the negotiated agreements we focused on the three musketeers as point predictions of bargaining outcomes in bankruptcy situations. Some authors (e.g., Selten 1987; Uhlich 1990), however, argue that actual behavior in bargaining and characteristic function games is better described by outcome areas instead of points. Kuon and Uhlich (1993) examined behavior in two-person characteristic function games by applying the Negotiation Agreement Area Theory (NAAT) developed by Uhlich (1990). We will follow their approach and examine area solutions of our bankruptcy games. In the course of the analysis we will adopt and extend the original NAAT to games with claims and introduce a claims adjusted NAAT.

The NAAT is based on the idea of aspiration levels players may form when entering a bargaining situation. For two-person characteristic function games minimal aspiration levels are assumed to be the stand-alone values of the single 'coalition'. In our bankruptcy games these values are simply given by the disagreement points. This implies that the minimal aspiration levels are given by $A_{i}^{\min }:=d_{i}=$ $0, i=1, \mathrm{w}$, where $1(\mathrm{w})$ stands for loser (winner). The maximal aspiration level of a player is assumed to be given by her marginal contribution to the grand coalition. In our bankruptcy games the value of the grand coalition is the estate $E$ and the stand-alone values are zero. Thus, when directly applying the definition of the maximal aspiration level we get $A_{i}^{\max }:=E$. However, bankruptcy games differ from usual bargaining situations by the existence of claims points. Therefore, it seems reasonable to adjust the maximal aspiration levels such that they are equal to the claims. The rationale for this adjustment is that in a bankruptcy situation no claimant can reasonably ask for more than her claims, since no impartial judge would allocate more than the claims to a claimant. We define, therefore, the 
claim adjusted maximal aspiration levels as $A_{i}^{\text {camax }}:=c_{i}, i=1$, w. A third kind of aspiration level defined in NAAT is the attainable aspiration level, which is for symmetric games - given by the maximum of the stand-alone value and the equal split of the grand coalition value. In our symmetric bankruptcy situations this reduces to $A_{i}^{\text {att }}:=E / 2, i=1$, w.

In the original NAAT for two-person characteristic function games it is argued that the stronger player (that is, the player with the higher stand-alone value in asymmetric games) has an advantage, because in case of disagreement she has less to lose. This argument is used to rationalize that the lower bounds of the NAA are calculated differently for the two players. In our bankruptcy games this argument has no bite since players are symmetric with respect to the disagreement payoff $d_{i}$. Hence, both players are treated as equally strong. Using the original definitions for the lower bounds this gives the bounds

$$
\mathrm{s}_{x_{i}}:=\frac{A_{i}^{\max }}{A_{\mathrm{w}}^{\max }+A_{1}^{\max }} E=\frac{E}{2}=\mathrm{EQUA}_{i}, \quad i=1, \mathrm{w},
$$

for the unadjusted maximal aspiration levels and

$$
{ }^{\mathrm{s}} \underline{x}_{i}^{\mathrm{ca}}:=\frac{A_{i}^{\text {camax }}}{A_{\mathrm{w}}^{\text {camax }}+A_{1}^{\text {camax }}} E=\frac{c_{i}}{c_{\mathrm{w}}+c_{1}} E=\mathrm{PROP}_{i}, \quad i=1, \mathrm{w},
$$

for the claim adjusted maximal aspiration levels. (The superscript $s$ indicates that these are bounds for a symmetric situation.) Hence, the NAAT reduces to a point solution and predicts the equal split in the unadjusted case and the proportional split in our claims adjusted approach.

Although, these solutions seem perfectly sensible one could argue that-despite of the equality of disagreement points - claimants differ in their bargaining powers because of their different claims. The player with the higher claim has more to lose in case of disagreement, what may make him more carefully in the bargaining process. Analogously to the arguments put forward in the original NAAT the "winner' in our games can therefore be viewed as the weaker player. This leads to new lower bounds for the NAAT for that player. Formally, in the original unadjusted approach the lower bounds for the winner and the loser are then given by

$$
{ }^{\text {as }} \underline{x}_{\mathrm{w}}:=\frac{A_{\mathrm{w}}^{\mathrm{att}}}{A_{\mathrm{w}}^{\mathrm{att}}+A_{\mathrm{l}}^{\max }} E=\frac{E}{3} \text { and }{ }^{\text {as }} \underline{x}_{1}:=\frac{A_{\mathrm{w}}^{\max }}{A_{\mathrm{w}}^{\max }+A_{1}^{\max }} E=\frac{E}{2} \text {, }
$$

respectively. (The superscript $a$ s indicates that these are bounds for an asymmetric situation.) In our claims adjusted approach these bounds are

$$
{ }^{\mathrm{as}} \underline{\mathrm{x}}_{\mathrm{w}}^{\mathrm{ca}}:=\frac{A_{\mathrm{w}}^{\mathrm{att}}}{A_{\mathrm{w}}^{\mathrm{att}}+A_{1}^{\mathrm{camax}}} E=\frac{E}{E+2 c_{1}} E
$$


Table 5 Predictions of area solutions with and without prominence level adjustment

\begin{tabular}{|c|c|c|c|c|c|c|}
\hline & \multicolumn{6}{|c|}{ Predictions without prominence level adjustment } \\
\hline & \multicolumn{3}{|l|}{$1640 \mathrm{E}$} & \multicolumn{3}{|l|}{$1980 \mathrm{E}$} \\
\hline & \multicolumn{2}{|l|}{ w_points } & w_share & \multicolumn{2}{|c|}{ w_points } & w_share \\
\hline EQUA & \multicolumn{2}{|l|}{1025} & 0.500 & \multicolumn{2}{|l|}{1025} & 0.500 \\
\hline CEA & \multicolumn{2}{|l|}{1200} & 0.585 & \multicolumn{2}{|l|}{1540} & 0.751 \\
\hline PROP & \multicolumn{2}{|l|}{1350} & 0.659 & \multicolumn{2}{|l|}{1630} & 0.795 \\
\hline CEL & \multirow{2}{*}{\multicolumn{2}{|c|}{1420}} & 0.693 & \multicolumn{2}{|l|}{1760} & 0.859 \\
\hline 'NAA & & & 0.500 & \multicolumn{2}{|l|}{1025} & 0.500 \\
\hline${ }^{\mathrm{s} N A A^{\mathrm{ca}}}$ & \multicolumn{2}{|l|}{1025} & 0.659 & \multicolumn{2}{|l|}{1630} & 0.795 \\
\hline as NAA & \multicolumn{2}{|c|}{$\begin{array}{l}1350 \\
{[350,1025]}\end{array}$} & {$[0.333,0.500]$} & \multicolumn{2}{|c|}{$[660,1025]$} & {$[0.333,0.500]$} \\
\hline${ }^{\text {as }} \mathrm{NAA}^{\mathrm{ca}}$ & \multicolumn{2}{|c|}{$[1121,1350]$} & {$[0.5467,0.659]$} & \multicolumn{2}{|c|}{$[1369,1630]$} & {$[0.668,0.795]$} \\
\hline & \multicolumn{6}{|c|}{ Predictions adjusted for prominence level $\Delta=25$} \\
\hline & \multicolumn{3}{|c|}{$1640 \mathrm{E}$} & \multicolumn{3}{|l|}{$1980 \mathrm{E}$} \\
\hline & w_points & w_share & Pred. success & w_points & w_share & Pred. success \\
\hline EQUA & 1025 & 0.500 & 0.1106 & 1025 & 0.500 & 0.4086 \\
\hline CEA & 1200 & 0.585 & 0.2217 & {$[1525,1550]$} & {$[0.744,0.756]$} & 0.0328 \\
\hline PROP & 1350 & 0.659 & 0.1106 & {$[1625,1650]$} & {$[0.793,0.805]$} & 0.0328 \\
\hline CEL & {$[1400,1425]$} & {$[0.683,0$.} & 95] -0.0127 & {$[1750,1775]$} & {$[0.854,0.866]$} & -0.0127 \\
\hline 'NAA & 1025 & 0.500 & 0.1106 & 1025 & 0.500 & 0.4086 \\
\hline${ }^{\mathrm{s}} \mathrm{NAA}^{\mathrm{ca}}$ & 1350 & 0.659 & 0.1106 & {$[1625,1650]$} & {$[0.793,0.805]$} & 0.0328 \\
\hline as NAA & {$[350,1025]$} & {$[0.171$,} & $00]-0.1074$ & {$[650,1025]$} & {$[0.317,0.500]$} & 0.2712 \\
\hline${ }^{\text {as }} \mathrm{NAA}^{\mathrm{ca}}$ & {$[1100,1350]$} & {$[0.537,0$.} & 59] 0.6554 & {$[1350,1650]$} & {$[0.659,0.805]$} & 0.1742 \\
\hline
\end{tabular}

and

$$
{ }^{\text {as }} \underline{x}_{1}^{\mathrm{ca}}:=\frac{A_{\mathrm{w}}^{\mathrm{camax}}}{A_{\mathrm{w}}^{\mathrm{camax}}+A_{\mathrm{l}}^{\mathrm{camax}}} E=\frac{c_{1}}{c_{\mathrm{w}}+c_{1}} E=\mathrm{PROP}_{1} \text {, }
$$

for the winner and the loser, respectively. ${ }^{9}$

In the upper part of Table 5 we summarize the area solutions discussed above and calculate the predictions for our particular bankruptcy situations. For convenience the predictions of the three musketeers and the equal split are also shown in the table. The lower part of Table 5 depicts the predicted areas of the solutions shown in the upper part after adjustment for the prominence level of our data set, which is $\Delta=25 .{ }^{10}$ For the calculation of the predictive success of a solution we use the success measure developed by Selten and Krischker (1983) and formally described by Selten (1991). This measure is defined as the difference between the relative frequency of correct predictions (hit rate) and the size of the predicted subset relative to the set of all possible outcomes. For instance, the predictive success of EQUA in $1640 \mathrm{E}$ is given by $1 / 9-1 / 2051=0.1106$. (There was exactly one

\footnotetext{
${ }^{9}$ We have also considered the alternative where it is assumed that the claimant with the lower claim is the weaker player. For the unadjusted approach this leads to lower bounds for the NAA of $E / 2$ for the winner and $E / 3$ for the loser. For the claims adjusted case the NAA is empty whenever $c_{1}<E / 2$, however. Since this holds for both of our bankruptcy situations we do not consider this case further. It is nevertheless interesting to note that if $c_{1} \geq E / 2$ then the winner's lower bound of the NAA is given by her proportional share. The lower bound for the loser is $\left[E /\left(2 c_{\mathrm{W}}+E\right)\right] E$.

${ }^{10}$ Interestingly, the prominence level of the negotiated agreements is different from the one of the normative judgments (see Sect. 4.1). A look at the data reveals that this is most likely due to the much higher frequency of equal splits in the negotiations.
} 
agreement - out of nine in total - giving the winner 1,025 points, the number of all possible winner shares in points is 2,051, and since EQUA is a point prediction the absolute area of prediction is 1.) Similarly, the predictive success of, e.g., ${ }^{\text {as }} \mathrm{NAA}^{\text {ca }}$ in $1980 \mathrm{E}$ is given by $7 / 22-301 / 2051=0.1742$. In the lower part of Table 5 this measure of predictive success is shown for the various solutions. We summarize the main findings in our next result.

Result 5 A comparison of success measures for prominence adjusted area solutions shows that in $1640 \mathrm{E}$ the asymmetric claims adjusted NAA predicts best, whereas in $1980 \mathrm{E}$ the point prediction EQUA, which coincides with the symmetric unadjusted NAA, has the highest predictive success.

\section{A 'beauty contest' of musketeers}

So far, our empirical strategy was to investigate which solution comes closest to the normative judgments, or negotiated agreements, by subjects who did not know explicitly about the solutions to claims problems. Thus, subjects could not for themselves evaluate the normative appeal of the various rules. To gain further insights into the perceived attractiveness of the four 'musketeers' and to complement our preceding evaluation of rules by direct evidence, we conducted a new survey study with another 59 subjects. These subjects had the same background as the other participants in our study. They had taken part neither in the experiments, nor the vignette studies.

We had the same treatments (i.e., claims points) as above, which we label 1980BC and 1640BC ('BC' stands for the 'beauty contest' described below). We gave the respondents the same description of the bargaining problem as in our previous vignette study. However, instead of asking them about their opinion how an arbitrator would solve the bankruptcy problem, we described the four rules to them and asked them to rank the rules according to their perceived attractiveness ('the beauty contest'). After the subjects read the same scenario as documented above, they were told the following (translated from German): ${ }^{11}$

Before the determination of the objective performance difference is finished (i.e., you cannot yet know whether you have the objectively higher or lower performance), you receive several proposals according to which fixed rule the new division of the budget shall be regulated in the future. It is foreseeable that the budget will change often:

EL: 'Equal Loss'. The reduction of the budget will be equally shared between the bargaining partners and deducted from their hitherto valid claims. In the above situation this rule would mean the following: The reduction of the budget amounts to 440 money units. This reduction will be borne equally by both, i.e., deducted from the hitherto valid claims. For the bargaining partner with the higher claim this rule would mean that his share now is $1,640-220=1,420$. The bargaining partner with the lower claim would, according to this rule, earn $850-220=630$ money units.

P: 'Proportional Division'. The new division is proportional to the hitherto valid division. In the above situation this rule would mean the following: According to the hitherto valid claims the budget would be divided in the proportion of the claims in the old budget (i.e., in the proportions $1640 / 2490$ and $850 / 2490$ resp.). With the new budget this rule would lead to an amount of 1350 [1630] money units for the higher claim and to 700 [420] money units for the lower claim $[2050 \times(1640 / 2490)=1350 ; 2050 \times(850 / 2490)=$ 700].

\footnotetext{
${ }^{11}$ Here we document the description of rules for 1640BC. In the 1980BC questionnaire, parameters were adapted accordingly.
} 
E: 'Equal Split'. The new budget will be split in equal parts. In the above situation this rule would mean the following: Both bargaining partners receive the same amount: $2050 / 2=1025$.

N: 'No Loss for the Lower Claim'. The lower claim will not be cut. In the above situation this rule would mean the following: The bargaining partner with the lower claim would also with the new budget earn 850 money units, i.e., his claim would not be cut. The claim of the bargaining partner with the higher claim would therefore be cut by 440 money units, i.e., by the total reduction of the budget and would therefore amount to $1640-440=1200$ money units.

The rules described for the subjects as 'EL', 'P', 'E', and 'N', correspond to CEL, PROP, EQUA, and CEA, respectively. The subjects then received a decision sheet on which they had to rank the four rules from first to fourth (i.e., from most preferred to least preferred). Thus, our subjects in this vignette study were in the same impartial situation as our subjects from the previous vignette study. However, they now could compare and judge the rules, which lead to a particular solution of the bankruptcy problem. This 'beauty contest' of rules yielded the following result:

Result 6 When asked to rank the 'musketeers', subjects overwhelmingly rank PROP first (and EQUA last) independent of the claims. When claims are very unequal subjects rank more egalitarian solutions slightly better than when claims are moderately unequal.

Support Table 6 depicts how often each rule was ranked first, second, etc. as well as the mean rank for both treatments. In both treatments the proportional rule was ranked first by most subjects. In 1980BC, PROP was ranked first in 19 out of 29 cases and in 1640BC it was ranked first even in 27 out of 31 cases. The average rank was 1.5 and 1.2 in $1980 \mathrm{BC}$ and $1640 \mathrm{BC}$, respectively. So there is no doubt

Table 6 A 'beauty contest' of rules

\begin{tabular}{lllll}
\hline Treatment & \multicolumn{3}{c}{ Solution } \\
\cline { 2 - 5 } & CEL & PROP & CEA & EQUA \\
\hline 1980BC & $5^{\mathrm{a}}$ & 19 & 3 & 2 \\
1st rank & 7 & 7 & 11 & 4 \\
2nd rank & 12 & 2 & 7 & 8 \\
3rd rank & 5 & 1 & 8 & 15 \\
4th rank & 2.6 & 1.5 & 2.7 & 3.2 \\
Mean rank & Second & First & Third & Fourth \\
Ranking of rules & & & & \\
1640BC & 4 & 27 & 0 & 0 \\
1st rank & 17 & 2 & 8 & 4 \\
2nd rank & 7 & 1 & 15 & 8 \\
3rd rank & 3 & 1 & 8 & 19 \\
4th rank & 2.3 & 1.2 & 3.0 & 3.5 \\
Mean rank & Second & First & Third & Fourth \\
Ranking of rules & 0.11 & 0.22 & 0.10 & 0.49 \\
$\chi^{2}$ test ${ }^{\text {b }} p$ values & & & & \\
\hline
\end{tabular}

${ }^{a}$ Numbers indicate the number of subjects who put the respective rule on the first, second, third and fourth rank, respectively

${ }^{\mathrm{b}} \chi^{2}$ tests compare the distribution of ranks between the different claims for each rule 
that the proportional rule is the most attractive musketeer and EQUA is the least attractive rule.

In the beauty contest the ranking of rules is stable across claims levels. None of the pairwise comparisons for a given rule returns a significant difference, although for CEL and CEA the $p$ values are close to being marginally significant. That is, the tendency is the same as in the vignettes and the experiments: in 1640BC, CEL is considerably more attractive than CEA (mean ranks are 2.3 and 3.0, respectively); whereas in 1980BC, CEL is only slightly better ranked than CEA.

\section{Concluding discussion}

In this paper we have taken an empirical approach to study bargaining problems with claims. We see our paper as complementary to the axiomatic characterization and game theoretic analyses that are prevalent in most of the literature. The results from this literature are important because they make the normative and strategic underpinnings of solution concepts transparent. However, for practical ends also sound empirical knowledge about the predictive power and practical sustainability of various derived rules is necessary.

We have argued that an empirical investigation of solution concepts involves two dimensions: the normative views people hold and the actual negotiation behavior when real money is at stake. To study the normative views we have developed two separate survey studies that use a vignette technique. For studying negotiation behavior we have designed a bargaining with claims experiment. To investigate the robustness of the solution concepts we also varied the claims points. To our knowledge no other study has combined these different research methods and variations in claims points in the empirical investigation of bargaining problems with claims.

We find that the proportional rule (PROP) does very well in people's normative judgments. In particular, PROP is the clear 'winner' in a 'beauty contest' of different rules. This holds irrespective of the asymmetry of claims. This might be not too surprising, since the proportionality principle has a long tradition as a principle of justice. It goes back to at least Aristotle: "Equals should be treated equally, and unequals, unequally in proportion to relevant similarities and differences" (see, e.g., Feldman 1999; E.E. Zajac, unpublished manuscript). This popularity of PROP is also consistent with 'equity theory' (e.g., Selten 1978) or the 'accountability principle (Konow 2000), which is related to equity theory. Equity theory argues with the relative value of 'inputs' (performance in our case) and 'outputs' (claims). Since the reduced pie does not affect this relative value, equity theory in this case predicts the proportional solution. According to the accountability principle, entitlements vary "in direct proportion to the value of the subject's relevant discretionary variables, ignoring other variables, but does not hold a subject accountable for the differences in the values of exogenous variables" (Konow 2000, p. 1075). In our case the discretionary variables is the performance, and the exogenous variable the pie reduction.

The appeal of CEL and CEA in the normative judgments depends to some extent on the asymmetry of claims. When claims are very asymmetric, people tend to prefer the 'more egalitarian' CEA rule whereas when claims are moderately asymmetric people tend to prefer the - in terms of outcomes - more inequitable CEL rule. 
We find a strong difference between the outcomes in actual negotiations and the normative judgments. While claims strongly matter for the normative judgments of how the surplus should be divided, actual negotiations moderate the effect of the difference in asymmetries in claims considerably. Additionally, compared to the normative judgments there is a strong level effect in so far that the actually agreed outcomes are closer to the equal split than the normative judgments would indicate. When looking at the point predictions of the three musketeers CEA predicts the actual agreements best for both claim levels. For negotiated outcomes we also look at area theories based on the Negotiation Agreement Area Theory taking also the prominence level of our data set into account. In this case we find that an area theory that is adjusted for the claims predicts best in case of the less asymmetric claims, whereas for the more asymmetric claims the equal split seems to be a good predictor.

How can we square the observation that PROP is the preferred rule in the normative judgments but more equal outcomes in the actual negotiations? We offer the following explanation. The impartial normative judgments show that the proportional solution is the most attractive focal point when there is no actual negotiation. Yet, when negotiations actually have to take place, the claims are infeasible and, hence materially irrelevant. Given the symmetric disagreement payoff of $(0,0)$, the equal split becomes another focal point. Moreover, when viewing (the last few seconds of) the free-form bargaining as a Nash demand game even every efficient allocation of the surplus can be sustained by a non-cooperative Nash equilibrium. Focal points are helpful in coordinating on one of the many equilibria. However, in the negotiations there is a tension between several reasonable focal points. This tension is the bigger the more asymmetric the claims are. This tension between the asymmetric outcome provided by PROP and the symmetric outcome of the equal split can explain why the variance in agreements is much larger in 1980E than in 1640E. Furthermore, the negotiation agreements indicate that outcomes between EQUA and PROP are attractive compromises for many actual bargainers.

The difference between normative judgments and actual negotiation behavior underscores the importance of studying both normative judgments and actual behavior. In our view, learning about impartial normative views and actual behavior when one is a stakeholder are complements, not substitutes. Learning about normative judgments tells us about likely focal points in the negotiations. The fact that we get different results in the experiment than in the normative judgments just illustrates that being a stakeholder matters strongly. This makes perfect sense for the following reasons. First, actual negotiations are strategic interactions with a threat point, where the disagreement results in a zero payoff for both, which may make the equal split another focal point. Second, in actual negotiations the opponents do not necessarily hold the same normative views. As we have shown elsewhere (Gächter and Riedl 2005), differences in normative attitudes indeed strongly shape the whole negotiation process. Third, it is a well-known tendency of people to subconsciously mix their normative views with what benefits them. This 'self-serving bias' can sometimes strongly influence negotiations (Babcock et al. 1995; Gächter and Riedl 2005). Fourth, negotiators differ in their degree of selfishness, toughness and willingness to compromise. Fifth, psychological research has shown that in many decisions there is a 'hot-cold' empathy gap (Loewenstein 2000). Being in the 'hot state' of an actual negotiation is psychologically a different matter than making 
a normative judgment while being in an impartial 'cold state'. All these factors can already be observed in a well-controlled and 'cool' laboratory environment. It is therefore very likely that they matter even more in outside-lab negotiations. The flip-side of these observations is that the study of normative views really requires impartiality.

Acknowledgements This paper is part of the EU-TMR research network ENDEAR (FMRXCT98-0238) and the research project on "Strategic Bargaining and Coalition Formation" financed by the Oesterreichische Nationalbank (project number 6933). We are very indebted to Franz Brandel who wrote the experimental software. Caroline Eckhart, Monika Egelwolf, Helmut Elsinger, Jens Großer, Markus Knell, Armin Schwienbacher and Jana Vyrastekova provided excellent research assistance. We thank participants of a seminar in Bielefeld for their helpful comments.

\section{Appendix: Distribution of normative judgments and bargaining outcomes (Fig. 4)}

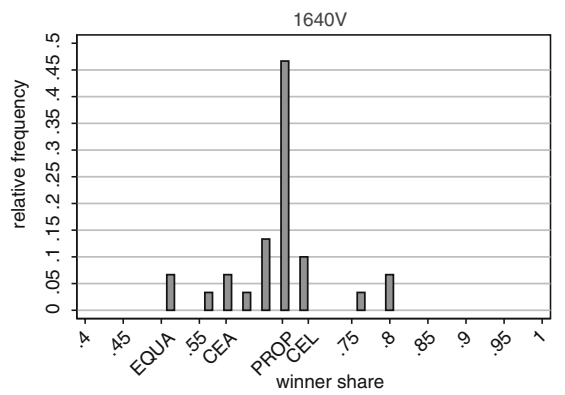

(a) Vignette with Claims $(1640,850)$

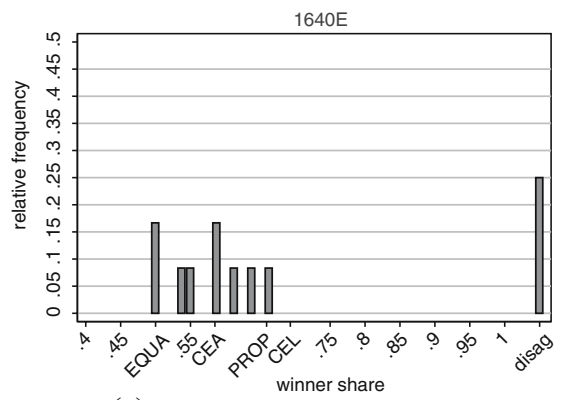

(c) Experiment With Claims $(1640,850)$

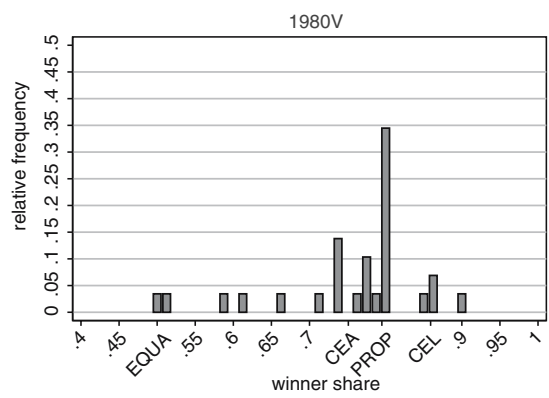

(b) Vignette With Claims $(1980,510)$

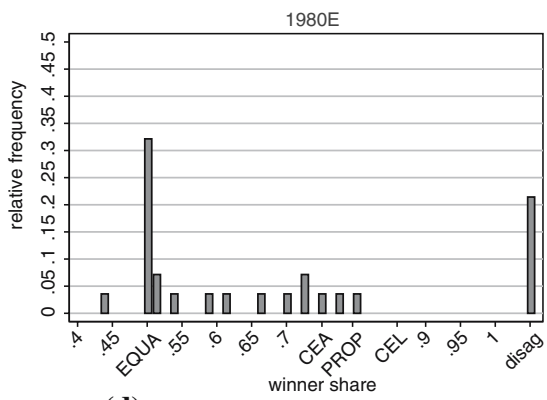

(d) EXPERIMENT WITH CLAIMS $(1980,510)$

Fig. 4 Distribution of normative judgments and bargaining outcomes (in winner share)

\section{References}

Albers W, Albers G (1983) On the prominence structure of the decimal system. In: Scholz RW (ed) Decision making under uncertainty. Elsevier, Amsterdam, pp 271-287

Aumann RJ, Maschler M (1985) Game theoretic analysis of a bankruptcy problem from the Talmud. J Econ Theory 36:195-213 
Babcock L, Camerer C, Issacharoff S, Camerer CF (1995) Biased judgments of fairness in bargaining. Am Econ Rev 85:1337-1343

Ball S, Eckel C, Grossman PJ, Zame W (2001) Status in markets. Q J Econ 116:161-188

Beckman SR, Formby JP, Smith JW, Zheng B (2002) Envy, malice and Pareto efficiency: an experimental examination. Soc Choice Welfare 19:349-367

Brandel F (2000) Rabbit: version 1.0. Mimeo, Institute for Advanced Studies, Vienna

Chun Y, Thomson W (1992) Bargaining problems with claims. Math Soc Sci 24:19-33

Chun Y, Schummer J and Thomson W (2001) Constrained egalitarianism: a new solution to bankruptcy problems. Seoul J Econ 14:269-297

Clark J (1998) Fairness in public good provision: an investigation of preferences for equality and proportionality. Can J Econ 31:708-729

Curiel I, Maschler M, Tijs SH (1987) Bankruptcy games. Z Oper Res 31:A143-A159

Dagan N (1996) New characterizations of old bankruptcy rules. Soc Choice Welfare 13:51-59

Dagan N, Volij O (1993) The bankruptcy problem: a cooperative bargaining approach. Math Soc Sci 26:287-297

Dagan N, Serrano R, Volij O (1997) A non-cooperative view of consistent bankruptcy rules. Games Econ Behav 26:55-72

Feldman B (1999) The proportional value of a cooperative game. Mimeo

Frohlich N, Oppenheimer JA (1990) Choosing justice in experimental democracies with production. Am Poli Sci Rev 84(2):461-477

Frohlich N, Oppenheimer JA, Eavey CL (1987) Choices of principles of distributive justice in experimental groups. Am J Polit Sci 31(3):606-637

Gächter S, Riedl A (2005) Moral property rights in bargaining with infeasible claims. Manage Sci 51(2):249-263

Gaertner W, Jungeilges J (2002) Evaluation via extended orderings: empirical findings from Western and Eastern Europe. Soc Choice Welfare 19:29-55

Gaertner W, Klemisch-Ahlert M (1992) Social choice and bargaining perspectives on distributive justice. Springer, Berlin Heidelberg New York

Gaertner W, Jungeilges J, Neck R (2001) Cross-cultural equity evaluations: A questionnaireexperimental approach. Eur Econ Rev 45:953-963

Herrero C, Villar A (2001) The three musketeers: four classical solutions to bankruptcy problems. Math Soc Sci 42:307-328

Herrero C, Moreno-Ternero JD, Ponti G (2004) On the adjudication of conflicting claims: an experimental study. Working paper, University of Alicante

Hoffman E, McCabe K, Shachat K, Smith V (1994) Preferences, property rights, and anonymity in bargaining games. Games Econ Beha 7:346-380

Kahneman D, Knetsch J, Thaler R (1986) Fairness as a constraint on profit seeking: Entitlements in the market. Am Econ Rev 76(4):728-741

Klemisch-Ahlert M (1996) Bargaining in economic and ethical environments. An experimental study and normative solution concepts. Springer, Berlin Heidelberg New York

Konow J (2000) Fair shares: accountability and cognitive dissonance in allocation decisions. Am Econ Rev 90:1072-1091

Konow J (2002) Which is the fairest one of all? A positive analysis of justice theories. J Econ Lit XLI:1188-1239

Kuon B, Uhlich GR (1993) The negotiation agreement area: an experimental analysis of twoperson characteristic function games. Group Decis Negotiat 2:323-345

Loewenstein G (2000) Emotions in economic theory and economic behavior. Am Econ Rev Pap Proc 90:426-432

Moulin H (1987) Equal or proportional division of a surplus, and other methods. Inter J Game Theory 16:161-186

Moulin H (2000) Priority rules and other asymmetric rationing methods. Econometrica 68:643684

Nydegger RV, Owen G (1975) Two-person bargaining: an experimental test of the Nash axioms. Inter J Game Theory 3:239-249

O’Neill B (1982) A problem of rights arbitration from the talmud. Math Soc Sci 2:345-371

Roth AE, Murnighan KJ (1982) The role of information in bargaining: an experimental study. Econometrica 50:1123-1142

Roth AE, Murnighan KJ, Schoumaker F (1988) The deadline effect in bargaining: some experimental evidence. Am Eco Rev 78:155-162 
Schokkaert E, Capeau B (1991) Interindividual differences in opinions about distributive justice. Kyklos 44(3):325-345

Schokkaert E, Overlaet B (1989) Moral intuitions and economic models of distributive justice. Soc Choice Welfare 6:19-31

Selten R (1978) The equity principle in economic behavior. In: Gottinger HW, Leinfellner W (ed) Decision theory and social effects. Kluwer, Dordrecht, pp. 289-301

Selten R (1987) Equity and coalition bargaining in experimental three-person games. In: Roth $\mathrm{AE}$ (ed) Laboratory experimentation in economics: six points of view. Cambridge University Press, Cambridge, pp 42-98

Selten R (1991) Properties of a measure of predictive success. Math Soc Sci 21:153-167

Selten R, Krischker S (1983) Comparison of two theories for characteristic function experiments. In: Tietz R (ed) Aspiration levels in bargaining and economics decision making. Springer, Berlin Heidelberg New York, pp 259-264

Thomson W (2003) Axiomatic and game-theoretic analyses of bankruptcy and taxation problems: a survey. Math Soc Sci 45:249-297

Uhlich GR (1990) Descriptive theories of bargaining: an experimental analysis of two- and three-person characteristic function bargaining. Lecture Notes in Economics and Mathematical Systems, No. 341. Springer, Berlin Heidelberg New York

Yaari ME, Bar-Hillel M (1984) On dividing justly. Soc Choice Welfare 1:1-24

Young HP (1988) Distributive justice in taxation. J Econ Theory 43:321-335 